\title{
VIDEOFLUOROSCOPIC SWALLOWING STUDY: esophageal alterations in patients with dysphagia
}

\author{
Betina SCHEEREN ${ }^{1,2}$, Antônio Carlos MACIEL ${ }^{3}$ and Sérgio Gabriel Silva de BARROS ${ }^{1,4}$
}

\begin{abstract}
Context - Videofluoroscopic swallowing study is a dynamic exam and allows the evaluation of the complete swallowing process. However, most published studies have only reported alterations in the oropharynx and pharyngoesophageal transition, leaving the analysis of the esophagus as a secondary goal. Objectives - The goal of this study was to investigate the prevalence of alterations in the esophageal phase thorough videofluoroscopic swallowing study in patients with dysphagia. Methods - Consecutive patients with dysphagia who underwent videofluoroscopic swallowing study including esophageal analysis between May 2010 and May 2012 had their exams retrospectively reviewed. Patients were classified into two groups: Group I - without a pre-established etiological diagnosis and Group II - with neurological disease. During the exam, the patients ingested three different consistencies of food (liquid, pasty and solid) contrasted with barium sulfate and 19 items were analyzed according to a protocol. The esophageal phase was considered abnormal when one of the evaluated items was compromised. Results - Three hundred and thirty-three $(\mathrm{n}=333)$ consecutive patients were studied - $213(64 \%)$ in Group I and $120(36 \%)$ in Group II. Esophageal alterations were found in $104(31 \%)$ patients, with a higher prevalence in Group I (36.2\%), especially on the items esophageal clearance (16.9\%) and tertiary contractions (16.4\%). It was observed that $12 \%$ of individuals in Group I only presented alterations on the esophageal phase. Conclusion - Evaluation of the esophageal phase of swallowing during videofluoroscopic swallowing study detects abnormalities in patients with cervical dysphagia, especially in the group without pre-established etiological diagnosis.
\end{abstract}

HEADINGS - Deglutition. Deglutition disorders. Fluoroscopy. Esophagus.

\section{INTRODUCTION}

Swallowing is a dynamic and complex process, and requires coordination of various structures that act in sequence to conduct food from the oral cavity to the stomach. It comprises three phases: oral, pharyngeal and esophageal. In the oral phase, the preparation, qualification, organization and ejection of food content from the oral cavity into the pharynx occur. The next phase of swallowing, which occurs in the pharynx, is characterized by the elevation, anteriorization and stabilization of the hyo-laryngeal complex, with airway closure and opening of the upper esophageal sphincter, which directs the bolus into the esophagus. The third and last phase, the esophageal phase, consists in transporting the food through the esophagus to the stomach ${ }^{(5,14)}$.

The swallowing disorder, named dysphagia, significantly compromises social and psychological relationships of the individual and is associated with significant morbidity and mortality ${ }^{(20)}$. Dysphagia may manifest through a series of signs and symptoms, such as: masticatory disorder; difficulty initiating swallowing; nasal regurgitation; coughing; choking; pharyngeal globus (sensation of food in the throat); alimentary impaction, which in more severe cases, can cause dehydration; malnutrition; weight loss; prolonged meal time; decreased appetite; and aspiration pneumonia with complications ${ }^{(9)}$.

The videofluoroscopic swallowing study (VFSS) has long been considered the "gold standard" for evaluation of swallowing disorders, since it allows the visualization of the entire swallowing process, detecting anatomical and functional disorders from the mouth to the esophagus and it might as well guide treatment progress ${ }^{(4,6)}$. During this exam, it is possible to offer different food consistencies with barium sulfate contrast, test maneuvers and facilitator postures that contribute to the assessment of the degree of dysphagia, thus enabling better planning of rehabilitation. The apparatus used for the procedure is a radiological equipment with image display connected to a DVD that allows recording for subsequent analysis, including use of slow motion for detailed investigation ${ }^{(12)}$. 
Most studies on VFSS have generally reported its use for identification of alterations in the oropharynx and pharyngoesophageal transition ${ }^{(12)}$. The exam is used in many centers, but its value to also detect alterations on the esophageal phase is not clearly defined. Dysphagia may be part of the clinical picture of many esophageal disorders, and it may be perceived and reported by the patient at the cervical region ${ }^{(17)}$. Thus, in patients with cervical dysphagia, it becomes important to evaluate the esophagus during the VFSS to verify anatomical modifications and functional alterations $s^{(3,5)}$. The purpose of this study was to investigate the prevalence of alterations on the esophageal phase through VFSS in patients with dysphagia.

\section{METHODS}

A retrospective analysis of consecutive VFSS in patients with dysphagia carried out between May 2010 and May 2012 at the Department of Radiology of the Hospital Santa Clara, Santa Casa de Misericórdia de Porto Alegre was conducted. The inclusion criteria for the study were patients referred for VFSS who had complaining of dysphagia and were older than 18 years of age. Exclusion criteria were gastrointestinal cancer, achalasia or incomplete examination protocol. Patients were divided into two groups for analysis: Group I - no pre-established etiological diagnosis and Group II - with neurological disease (stroke, Parkinson's disease, Alzheimer's disease, traumatic brain injury, dementia, amyotrophic lateral sclerosis, multiple sclerosis, myasthenia gravis and muscular dystrophy).

The protocol used was modified from Furkim (1999)(7) and consisted of 19 items on swallowing evaluation (oral, pharyngeal and esophageal phases). The protocol was completed by a Speech-Language Pathologist and a Radiologist Medical Doctor during the examination. All exams were reviewed by two professionals and archived at the radiology department. The data were stored in a database in a Microsoft Office Excel 2007 spreadsheet, and the survey of archived data was conducted by the authors of this study.

The exams were performed with a Siemens fluoroscopy unit, model Axion Iconos R100, coupled to a computerized image recording system that allowed detailed analysis of the exam. During the realization of VFSS, patients remained seated and image capture was obtained at lateral and anterior-posterior positions, with upper and lower limits ranging from the oral cavity to the stomach.

The protocol included functional intake of liquid, pasty and solid consistencies. The preparation of food occurred as follows:

- Liquid consistency: distilled water with liquid barium (Bariogel $\left.{ }^{\circledR}\right)$ - ratio of 1:1 (40 mL of water to $40 \mathrm{~mL}$ of barium - with $20 \mathrm{~mL}$ per swallow);

- Pasty consistency: yogurt with liquid barium (Bariogel ${ }^{\circledR}$ ) - 1:1 ratio $(20 \mathrm{~mL}$ of yogurt to $20 \mathrm{~mL}$ of barium - with 10 $\mathrm{mL}$ per swallow);

- Solid consistency: breadcrumbs soaked in liquid barium $\left(\right.$ Bariogel $\left.^{\circledR}\right)$.
For the esophageal analysis a larger volume (80 to 100 $\mathrm{mL}$ ) with 50\% diluted liquid barium was used.

Our used the liquid was classified as "nectar" and the viscosity of the pasty as "pudding" according to the guidelines of the National Dysphagia Diet ${ }^{(19)}$.

Variables such as gender, age, etiology, alimentary route and complains reported by the patient were tabulated. Regarding the assessment of the VFSS the following items of the referred protocol were considered:

- Oral phase: anterior escape, bolus capture, labial closure, preparation and positioning of the bolus, ejection, posterior escape and stasis of food;

- Pharyngeal phase: sealing of velopharyngeal region, laryngeal elevation, stasis of food in valleculas and piriform sinuses, laryngeal penetration and tracheal aspiration;

- Pharyngoesophageal/esophageal phase: opening of the upper esophageal region, esophageal clearance, pharyngoesophageal and/or esophageal diverticulum and tertiary contractions.

Continuous variables were expressed as mean and standard deviation or median and interquartile range. Categorical variables were described by absolute and relative frequencies. The Student $t$ test was applied to compare means between groups. In the case of asymmetry, the Mann-Whitney test was used. In the between-group comparison of proportions, the Pearson chi-square test or Fisher's exact test was applied. The level of significance was $5 \%(P \leq 0.05)$ and analyzes were performed using SPSS (Statistical Package for the Social Sciences) version 18.0.

This project was approved by the Ethics Committee of the Santa Casa de Misericórdia de Porto Alegre under protocol number 70367. A Confidentiality Agreement for use of the data collected was applied. This study follows the rules of Resolution 196/96 CNS / MS.

\section{RESULTS}

Three hundred and thirty-three patients $(\mathrm{n}=333)$ met the inclusion criteria of the study conducted between May 2010 and May 2012. The average age was 64 years ( \pm 16.6 years) and $184(55 \%)$ participants were female. The most common complaint reported by the patient was "swallowing difficulty" (51.4\%), followed by "choking and coughing" $(35.3 \%)$ and "sensation of food in the throat" (13.3\%). Two hundred and thirteen $(64 \%)$ patients did not have pre-established etiological diagnosis for dysphagia and 120 $(36 \%)$ with neurologic disease. Most patients $(94.4 \%)$ were ingesting food orally, and the remainder had exclusive or mixed alternative feeding means, that is, oral concomitantly with enteral route.

Among the 333 exams conducted, $60(18 \%)$ patients had no alteration in swallowing, $104(31 \%)$ had abnormalities in the esophageal phase of swallowing, $220(66 \%)$ in the oral phase and $133(40 \%)$ in the pharyngeal phase. The comparative analysis of alterations in the swallowing phases between Group I (without pre-established diagnosis) versus Group II (with neurological disease) is shown in Table 1. 
TABLE 1. Comparative analysis of alterations in the swallowing phases between Group I and Group II

\begin{tabular}{|c|c|c|c|}
\hline \multirow[t]{2}{*}{ Protocol items } & $\begin{array}{l}\text { GROUP I } \\
(\mathrm{n}=213)\end{array}$ & $\begin{array}{c}\text { GROUP II } \\
(\mathrm{n}=120)\end{array}$ & \multirow[t]{2}{*}{$P$} \\
\hline & $\mathrm{n}(\%)$ & $\mathrm{n}(\%)$ & \\
\hline General oral phase ${ }^{\#}$ & $130(61.0)$ & $107(89.2)$ & $<0.001 * *$ \\
\hline Anterior scape & $0(0.0)$ & $2(1.7)$ & $0.129 *$ \\
\hline Bolus capture & $5(2.3)$ & $15(12.5)$ & $<0.001 * *$ \\
\hline Labial closure & $3(1.4)$ & $7(5.8)$ & $0.039 *$ \\
\hline Bolus preparation & $43(20.2)$ & $89(74.2)$ & $<0.001 * *$ \\
\hline Bolus positioning & $45(21.1)$ & $89(74.2)$ & $<0.001 * *$ \\
\hline Ejection & $25(11.7)$ & $59(49.2)$ & $<0.001 * *$ \\
\hline Posterior scape & $120(56.3)$ & $102(85.0)$ & $<0.001 * *$ \\
\hline Food stasis & $1(0.5)$ & $8(6.7)$ & $0.002 *$ \\
\hline Number of alterations $\dagger$ & $1(0-1)$ & $3(1-4)$ & $<0.001 * * *$ \\
\hline General pharyngeal phase $\mathrm{e}^{\#}$ & $57(26.8)$ & $69(57.5)$ & $<0.001$ \\
\hline Velopharyngeal region closure & $6(2.8)$ & $5(4.2)$ & $0.534 *$ \\
\hline Laryngeal elevation & $3(1.4)$ & $5(4.2)$ & $0.142 *$ \\
\hline Food stasis vallecula & $47(22.1)$ & $53(44.2)$ & $<0.001 * *$ \\
\hline Food stasis piriform recess & $25(11.7)$ & $27(22.5)$ & $0.015 * *$ \\
\hline Laryngeal penetration & $20(9.4)$ & $28(23.3)$ & $0.001 * *$ \\
\hline Tracheal aspiration & $11(5.2)$ & $17(14.2)$ & $0.008 * *$ \\
\hline Number of alterations $\dagger$ & $0(0-1)$ & $1(0-2)$ & $<0.001 * * *$ \\
\hline General esophageal phase ${ }^{\#}$ & $77(36.2)$ & $27(22.5)$ & 0.014 \\
\hline Opening of superior esophageal region & $13(6.1)$ & $4(3.3)$ & $0.399 * *$ \\
\hline Esophageal clearing & $36(16.9)$ & $11(9.2)$ & $0.075 * *$ \\
\hline Pharyngoesophageal diverticulum & $9(4.2)$ & $3(2.5)$ & $0.548 *$ \\
\hline Esophageal diverticulum & $7(3.3)$ & $2(1.7)$ & $0.497 *$ \\
\hline Tertiary contractions & $35(16.4)$ & $14(11.7)$ & $0.309 * *$ \\
\hline Number of alterations $\dagger$ & $0(0-1)$ & $0(0-0)$ & $0.010 * * *$ \\
\hline
\end{tabular}

\# considered abnormal if alteration is present in at least one of the phase components; $\uparrow$ described by medians (percentile $25-75$ ) * Fisher's exact test, ** Pearson chi-square test;

*** Mann-Whitney test

It was observed that in individuals with pre-established etiological diagnosis (Group II), there was a significant predominance of alterations in the oral $(P<0.001)$ and pharyngeal $(P<0.001)$ phases when compared to Group I. However, in the group without pre-established etiological diagnosis this finding is reversed, and alterations in the esophageal phase generally occurred in $36.2 \%$ (Group I) versus $22.5 \%$ (Group II) of participants $(P=0.014)$. This difference, however, was not observed for the items separately. The most affected items of esophageal phase was esophageal clearance $(17 \%)$ and tertiary contractions $(16 \%)$.

Alterations in each phase of swallowing in isolation and combined are displayed in Figure 1. Statistical difference between Group I and Group II was observed in the esophageal phase alone ( $12 \%$ of alterations in Group I), when combining pharyngeal and esophageal phases (4\% in Group I), oral

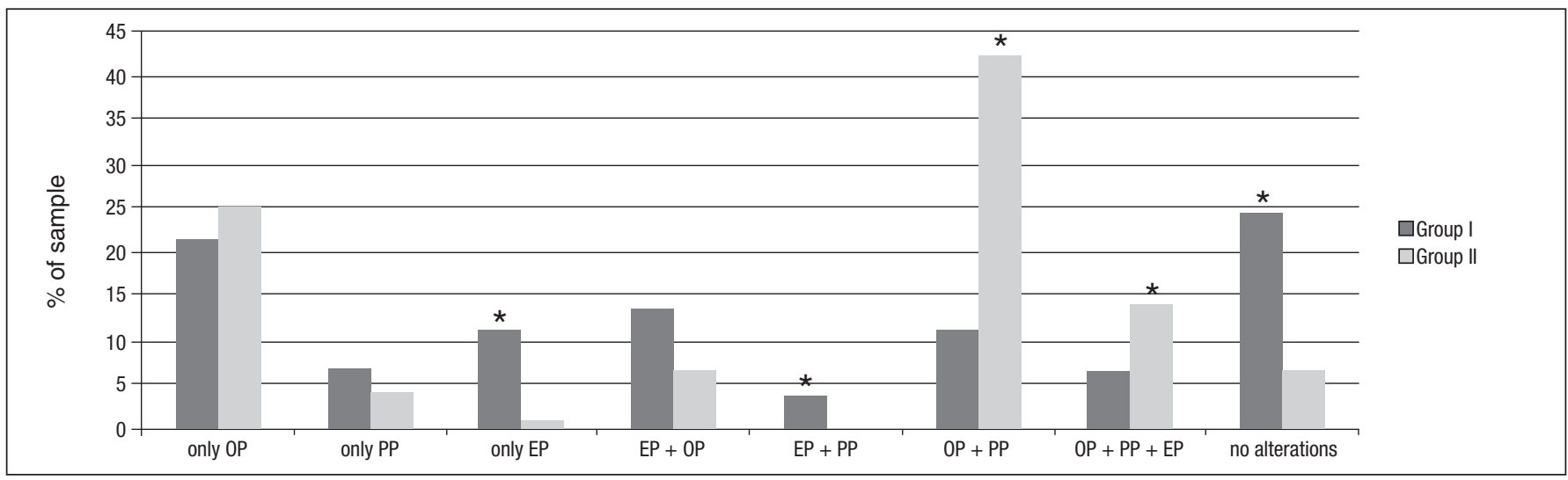

FIGURE 1. Analysis of the swallowing phases in isolation and combined OP: oral phase; PP: pharingeal phase; EP: esophageal phase. $P<0.05$. 
and pharyngeal phases ( $42 \%$ in Group II), the three phases of swallowing (14\% in Group II), and in the group without alteration ( $24 \%$ in Group I).

\section{DISCUSSION}

In our study we noted the importance of evaluating the three phases of swallowing (oral, pharyngeal and esophageal), especially in patients who do not have a pre-established diagnosis of dysphagia. It should be emphasized that onethird of the patients had some abnormality in the esophageal phase that could be unnoticed if a complete evaluation had not been not performed.

Alterations in the esophageal phase were found in 104 (31\%) participants from the two groups, especially in the group without pre-established etiological diagnosis, and $12 \%$ of patients in that group showed alterations only on the esophageal phase, with a predominance of the items "esophageal clearance" and "tertiary contractions". These findings are considered indicative of primary or secondary motor disorders of the esophagus ${ }^{(18)}$. The presence of defined anatomical alterations, such as pharyngoesophageal and/or esophageal diverticula occurred at a low frequency.

In the group of patients with pre-established etiological diagnosis (Group II), there was a concentration of concomitant alterations in the oral and pharyngeal phases, reinforcing the interdependence between these phases and the artificiality of separating swallowing into isolated phases ${ }^{(13)}$.

Allen et al. (1) included a screening of the esophageal phase on the swallowing videofluoroscopy protocol with the ingestion of $20 \mathrm{~mL}$ of liquid barium in the anterior-posterior vision after completing the oropharyngeal evaluation and compared the findings with conventional radiography of the esophagus. They observed that the first examination had a positive agreement in nearly $3 / 4$ of the subjects in relation to the second examination. The authors identified $63 \%$ of patients with possible esophageal disorder whose diagnosis could not have been observed if screening of the esophagus during the dynamic test had not been performed. In our study, the evaluation of the esophageal phase in the anteriorposterior vision covered, besides the ingestion of $20 \mathrm{~mL}$ of liquid barium, the ingestion of pasty and solid food, detecting $31 \%$ of patients with an alteration on this swallowing phase.

Gullung et al ${ }^{\left({ }^{(8)}\right.}$ presented results with a significant relationship between esophageal involvement in VFSS and abnormal esophageal motility testing. Of the 164 patients, 104 presented esophageal clearance component alteration, which assesses esophageal phase on the videofluoroscopy assessment protocol. The esophageal evaluation by VFSS measured by esophageal impedance measure - considered the gold standard test to evaluate esophageal motility - showed a sensitivity of $80 \%$.
When evaluating the role of VFSS in detecting structural abnormalities in the digestive tract, Scharitzer et al. ${ }^{(16)}$ observed a high frequency of both morphological and functional disorders, including mass lesions in the oral and pharyngeal cavity, stenosis, esophageal rings - alterations not found in this study - and pharyngeal and esophageal diverticulum, always pointing to the cervical region. Mendell and Logemann ${ }^{(15)}$ allege that the esophageal clearance in the upright position seems to have a functional impact in the pharynx and possibly in airway protection. The fluoroscopic evaluation of the esophageal phase should be consider a mean to evaluate esophageal motility compared with esophageal manometry, which is the procedure used to evaluate the esophageal sphincter, contraction and peristalsis of the esophageal body ${ }^{(10)}$. In the literature, there are studies demonstrating high agreement between VFSS and manometry in patients with dysphagia ${ }^{(3,8)}$.

The VFSS is an exam that can simultaneously detect both structural and functional changes in the oropharyngeal and esophageal regions. Patients presenting alterations of the esophageal phase should be investigated through more specific tests, such as endoscopy, esophageal manometry and esophageal pH metry, because the VFSS is a screening tool that can aid in selection of other tests and disclose diagnosis of esophageal disorders ${ }^{(1,2,11,16,18)}$.

Importantly, the screening of the esophageal phase of swallowing through videofluoroscopy is of short duration and can be easily carried out. Several studies define the esophageal transit time at approximately 13 seconds and less than $0.1 \mathrm{mGy}$ of radiation is used during the esophageal screening period. This value is much lower than those estimated of radiation per year ( $3 \mathrm{mGy}$ ) or dose received on CT of the abdomen $(10 \mathrm{mGy})^{(1)}$.

The main limitation in this study was the fact that it consisted of a retrospective study. Therefore, it was not possible to follow the evolution of the patients and to verify the sequence of assessments and final diagnosis in relation to esophageal phase alterations found through the VFSS. As Gullung et al..$^{(8)}$, we also suggest that prospective studies observe further esophageal evaluation that can provide more definite evidence that the VFSS application in the esophageal phase can serve as screening for disorders of esophageal motility.

\section{CONCLUSION}

The VFSS identified esophageal alterations in one third of patients with dysphagia. The prevalence of alterations was higher in Group I and 12\% of patients in that group showed alterations only in the esophageal phase. The realization of VFSS including the esophageal phase is a screening tool that can guide further investigation of the esophagus and contribute to the understanding of the complaints of the patient. 
Scheeren B, Maciel AC, Barros SGS. Videofluoroscopia da deglutição: alterações esofágicas em pacientes com disfagia. Arq Gastroenterol. 2014,51(3):221-5.

RESUMO - Contexto - A videofluoroscopia da deglutição é um exame dinâmico e permite a avaliação de todo o processo da deglutição, entretanto, a maioria dos estudos publicados relata apenas alterações na orofaringe e transição faringoesofágica, não considerando como importante as alterações esofágicas. Objetivos - O objetivo da presente pesquisa foi verificar a prevalência de alterações na fase esofágica à videofluoroscopia da deglutição em pacientes com disfagia. Métodos - Pacientes com queixa de disfagia submetidos à videofluoroscopia da deglutição incluindo estudo esofágico entre maio de 2010 e maio de 2012 tiveram seus exames revisados retrospectivamente. Os pacientes foram classificados em dois grupos: Grupo I - sem diagnóstico etiológico pré-estabelecido e Grupo II - com diagnóstico de doença neurológica. Durante o exame os pacientes ingeriram três consistências de alimento (líquido, pastoso e sólido) contrastadas com sulfato de bário e 19 itens foram analisados segundo protocolo. A fase esofágica foi considerada alterada quando um dos itens avaliados estivesse comprometido. Resultados - Trezentos e trinta e três ( $\mathrm{n}=333$ ) pacientes consecutivos foram estudados com 213 (64\%) no Grupo I e 120 (36\%) no Grupo II. Alterações esofágicas foram identificadas em 104 (31\%) pacientes, sendo a prevalência maior no Grupo I (36,2\%), principalmente, nos itens clareamento esofágico $(16,9 \%)$ e contrações terciárias (16,4\%). Pudemos observar que $12 \%$ dos indivíduos do Grupo I apresentaram somente alteração em fase esofágica. Conclusão - Avaliação da fase esofágica durante a videofluoroscopia da deglutição identificou alterações esofágicas em 1/3 dos pacientes com queixa de disfagia cervical, principalmente no grupo sem diagnóstico etiológico pré-estabelecido.

DESCRITORES - Deglutição. Transtornos de deglutição. Fluoroscopia. Esôfago.

\section{REFERENCES}

1. Allen JE, White C, Leonard R, Belafsky PC. Comparison of esophageal screen findings on videofluoroscopy with full esophagram results. Head Neck. 2012;34:264-9.

2. Chen CL, Orr WC. Comparison of Esophageal Motility in Patients with Solid Dysphagia and Mixed Dysphagia. Dysphagia. 2005;20:261-5.

3. Cho TK, Choi MG, Oh SN, Baik CN, Park JM, Lee IS, et al. Comparisons of bolus transit patterns identified by esophageal impedance to barium esophagram in patients with dysphagia. Dis Esophagus. 2012;25:17-25.

4. Costa MMB, Nova JLL, Carlos MT, Pereira AA, Koch HA. Videofluoroscopy -a new method. Radiol Bras. 1992;25:11-8.

5. Costa MMB. Estudo qualitativo da deglutição pelo método videofluoroscópico. In: Furkim AM, Santini CRQS. Disfagias orofaríngeas. São Paulo: Pró-Fono; 2008. p. $173-88$

6. Costa MMB. Videofluoroscopy: the gold standard exam for studying swallowing and its dysfunction. Arq Gastroenterol. 2010;47:327-8.

7. Furkim AM. Protocolo de Videofluoroscopia da Deglutição. In: Programas de Reabilitação em Disfagia Neurogênica. São Paulo: Frôntis Editorial; 1999.

8. Gullung JL, Hill EG, Castell DO, Martin-Harris B. Oropharyngeal and Esophageal Swallowing Impairments: their association and the predictive value of the modified barium swallow impairment profile and combined multichannel intraluminal impedance-esophagealmanometry. Ann Otol Rhinol Laryngol. 2012;121:738-45.

9. Karkos PD, Papouliakos S, Karkos CD, Theochari EG. Current evaluation of the dysphagic patient. Hippokratia. 2009;13:141-6.

10. Katz PO, Menin RA, Gideon M. Utility and Standards in Esophageal Manometry. J Clin Gastroenterol. 2008;42:620-6.
11. Levine MS, Rubesin SE, Laufer I. Barium Esophagography: A Study for All Seasons. Clin Gastroenterol Hepatol. 2008;6:11-25.

12. Martin-Harris B, Jones B. The Videofluorographic Swallowing Study. Phys Med Rehabil Clin N Am. 2008;19:769-85.

13. Martin-Harris B, Michel Y, Castell DO. Physiologic model of oropharyngeal swallowing revisited. Otolaryngol Head Neck Surg. 2005;133:234-40.

14. Matsuo K, Palmer JB. Anatomy and Physiology of feeding and swallowing: normal and abnormal. Phys Med Rehabil Clin N Am. 2008;19:691-707.

15. Mendell DA, Logemann JA. A Retrospective Analysis of the Pharyngeal Swallow in Patients with a Clinical Diagnosis of GERD Compared with Normal Controls: A Pilot Study. Dysphagia. 2002;17:220-6.

16. Sharitzer M, Pokieser P, Schober E, Schima W, Eisenhuber E, Stadler A, et al Morphologic findings in dynamic swallowing studies of symptomatic patients. Eur Radiol. 2002;12:1139-44.

17. Smith DF, Ott DJ, Gelfand DW, Chen, MYM. Lower esophageal mucosal ring: correlation of referred symptoms with radiographic findings using a marshmallow bolus. AJR. 1998;171:1361-5.

18. Summerton S. Radiographic Evaluation of Esophageal Function. Gastrointest Endoscopy Clin N Am. 2005;15:231-42.

19. The National Dysphagia Diet: standardization for optimal care. Chicago, IL: American Dietetic Association, 2002.

20. Wilkins T, Gillies RA, Thomas AM, Wagner PJ. The prevalence of dysphagia in primary care patients: a hamesnet research network study. J Am Board Fam Med. 2007;20:144-50. 